\title{
Chemo-preventive Activities of Common Vegetables’ Volatile Organic Compounds (VOCs)
}

\author{
Ola Lasekan* and Shakirah Azeez \\ Faculty of Food Science and Technology, University Putra Malaysia, Serdang, Malaysia
}

\begin{abstract}
In the last few years, many research reports on the chemo-preventive activities of vegetables have been published. Vegetables are not only nutrient-dense food source but they are also rich in volatile organic compounds with known bioactivities beneficial to human health. A review of vegetables volatile constituents and their bioactivities is therefore important. It will display an overview and information regarding their role in the improvement of human health. The current status of research on volatile organic compounds in common vegetables and their potential roles in the prevention of various diseases associated with oxidative stress, such as cardiovascular and neurodegenerative diseases are reviewed. The major volatile compounds with roles in cardiovascular and neurodegenerative disease prevention are benzene propane nitrile commonly found in (Broccoli raab), hydroxycinnamates (lettuce), xanthorrihzol (artichoke), dially sulfide (onion and garlic), allicin (onion and garlic), and anthraquinone (rhubarb). The anti-microbial, anti-oxidant, and anti-thrombotic activities of other compounds such as trans-ocimene, $\beta$-selinene, fenchone, carotol, and others are also reported.
\end{abstract}

Keywords: Chemo-preventive activities; vegetables; volatile organic compounds

\section{Practical Application}

In recent years, common vegetables have become very attractive for consumers because of their potentially beneficial volatile compounds contained in them. However, the role played by volatile organic compounds in disease prevention has not received the same attention.

\section{Introduction}

Vegetables can be said to either directly or indirectly supply all foods for humans. They are edible plant products which can be modified. Their important parts are stems, roots, leaves, flowers and fruits. They are usually categorized on the basis of the plant part that is used for food. Stem vegetables include kohlrabi, celery, and asparagus. Radishes, turnips, carrots, and beets are classified as root vegetables. Leafy vegetables include the cruciferous kale, endives, and lettuce. The flowery parts of vegetables are the broccoli, cauliflower, leeks, artichoke and the Allium genera. The fruits are structures usually containing seeds which develop after fertilization or pollination [1]. Thus, eggplants, cucumber, beans, squash, bell peppers, corn and tomatoes fall into this category.

Flavor compounds in vegetables are contained in the intact tissues as non-volatile precursors which become volatile by enzymatic actions once the tissue is disrupted by crushing, cutting or shredding. Vegetable volatiles are nitrogen and sulphur compounds, and carbonyls [2]. Vegetables are not only nutrient-dense food sources, but they are also rich sources of bioactive volatile organic compounds (VOCs). VOCs are organic compounds with high vapor pressure at room temperature. VOCs are many, ubiquitous and include naturally occurring chemicals. Most scents or odors are regarded as VOCs. Literature sources have shown that a multitude of bioactive compounds in vegetables have anticarcinogenic properties $[3,4]$. These nutrient-dense and bioactive volatile foods have the potential to protect against chronic and degenerative diseases including diabetes and cardiovascular diseases $[5,6]$. The aim of the study is to review the bioactivities of volatile organic constituents of common vegetables in human health.

\section{Materials and Methods}

\section{Fruit part of vegetables}

Bell Pepper (Capsicum annuum): Capsicum annuum also called bell pepper or sweet pepper are native plants of America, and the fruits are grown for consumption as vegetables, spices, and external medicines [7]. Capsicums are used primarily in food because of their pungency and colour [7]. Apart from capsaicinoids, a secondary metabolite of pepper, which gives pepper its pungency, other volatile constituents include trans-beta-ocimene, limonene, methyl salicylate and linalool (Table 1) [8]. Whole dried pepper fruits have been used as traditional grain protectant in West Africa [9]. Admixture of dry pepper powder and cowpea has been known to cause $46 \%$ mortality in adult C. maculates, a common pest of stored legumes. The ethanol extracts of bell pepper have been shown to cause $100 \%$ adult mortality in T. confusum after a five days exposure period. Perry, [10] reported the major constituents to be capsicine, capsaicin, capsanthine, capsorubine, carotene and carotenoids respectively. Diterpenoid glycosides isolated from the fruit C. annuum exhibited anti-hypertensive effects $[11,12]$.

Cucumber (Cucumis sativus, L.): C. sativus belongs to the same cucurbitaceae family as squash, muskmelon and watermelon. It's a seasonal vegetable crop native to India [13]. All the parts of this plant (leaf, fruit, and seed) have been explored for their therapeutic benefits. Cucumber is widely used for various skin problems and it's believed to promote cooling, healing, soothing, emollient, and anti-itching effect on irritated skin. The leaves, stems and roots are generally used

*Corresponding author: Ola Lasekan, Faculty of Food Science and Technology, University Putra Malaysia, Serdang, Malaysia, Tel: +603 8946 8535; Fax: +603 8942 3552; E-mail: lasekan@upm.edu.my, olaniny56@gmail.com

Received June 30, 2014; Accepted July 30, 2014; Published August 07, 2014

Citation: Lasekan O, Azeez S (2014) Chemo-preventive Activities of Common Vegetables' Volatile Organic Compounds (VOCs). Pharm Anal Acta 5: 306. doi:10.4172/2153-2435.1000306

Copyright: ( $) 2014$ Lasekan O, et al. This is an open-access article distributed under the terms of the Creative Commons Attribution License, which permits unrestricted use, distribution, and reproduction in any medium, provided the original author and source are credited. 
Citation: Lasekan O, Azeez S (2014) Chemo-preventive Activities of Common Vegetables' Volatile Organic Compounds (VOCs). Pharm Anal Acta 5: 306. doi:10.4172/2153-2435.1000306

Page 2 of 8

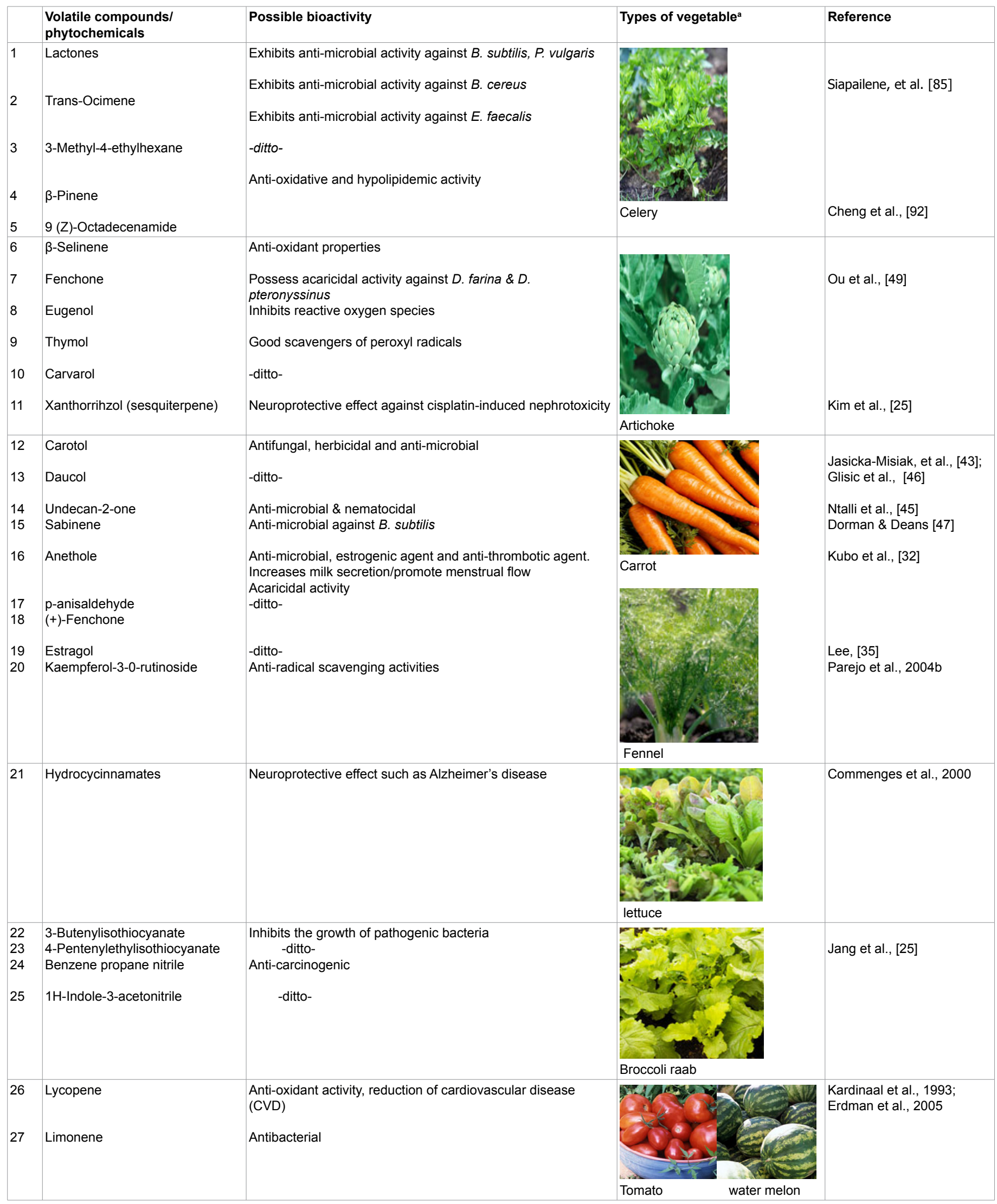


Citation: Lasekan O, Azeez S (2014) Chemo-preventive Activities of Common Vegetables' Volatile Organic Compounds (VOCs). Pharm Anal Acta 5: 306. doi:10.4172/2153-2435.1000306

Page 3 of 8

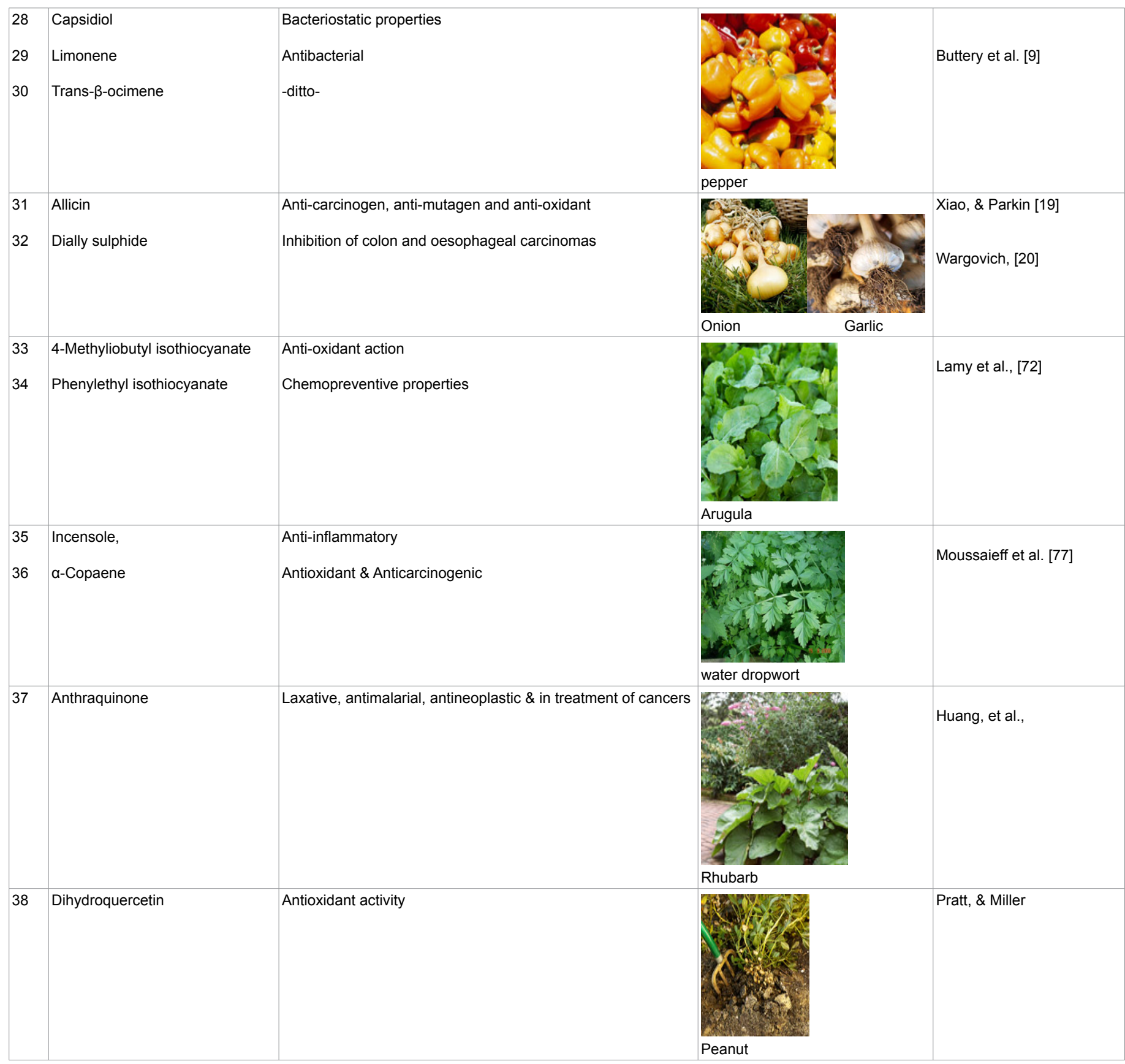

ahttp://www.bhg.com/gardening/plant-dictionary/vegetables

Table 1: Some volatile constituents of common vegetables and their possible bioactivities.

as anti-diarrheal, detoxicant and anti-gonorrhoeal agents among the Chinese folks. Cucumber potentials as an antioxidant, anti-wrinkle, antimicrobial, anti-diabetic, and hypolipidemic agents have been well documented.

The presence of cucurbitacin (a triterpenoid substance) in cucumber seed has been attributed to its cytotoxicity and anti-cancer activities. Guha and Sen [14] reported that cucurbitacin also exhibited wide ranges of in-vitro and in-vivo pharmacological effects and is used as purgative, anti-inflammatory and anti-fertility agent. The volatile oils of $C$. sativus have been reported to show antibacterial activity (MIC=0.09-0.5 mg/
$\mathrm{mL}$ ) against both gram-positive and gram-negative bacteria [15], and anti-fungal activity against human pathogen fungi (C. albicans, $C$. tropicalis, and C. glabrata) [16]. Similarly, (E,Z)-2,6-nonadienal and (E)-2-nonenal, the major volatile constituents present in cucumber have been reported to show anti-bacterial activity against human and food borne pathogen bacteria, such as Bacillus cereus, Escherichia coli, Listeria monocytogenes and Salmonella typhirium [16]. Stratil et al. [17] reported that cucurbitacin D and 23,24-dihydrocucurbitacin D, isolated from cucumber extracts significantly inhibited tyrosinase and melanin synthesis. 


\section{Root part of vegetables}

Onions (Allium cepa L): Onion is one of the major vegetable crops grown in the world.

The complex aroma, flavour, and lachrymatory characteristics of onion have been attributed to a variety of sulphur compounds. Allicin and its derivatives are one of the major sulphur-containing volatile compounds in Allium species such as onion, and Allicin is known to have curative as well as potential anti-carcinogenic, anti-mutagenic, and antimicrobial properties (Table 1) $[18,19]$. It is well known that both oil-soluble and water-soluble organo-sulphur compounds (OSCs) are contained in onions, some of which have been shown to be chemopreventive against carcinogenesis in animal models. Some studies have reported that dially sulphide (DAS) inhibits development of colon carcinomas, oesophageal carcinomas, pulmonary adenomas, and forestomach tumours in rodents when administered prior to carcinogen exposure [20]. However, Fukushima, Takada, Hori, and Wanibuchi [21] observed that water-soluble OSCs have inhibitory effect on rat liver carcinogenesis in second stage growth. S-Allylcysteine, S-propylcysteine, S-ethylcysteine, S-methylcysteine and cysteine, decreased GST-P-positive foci (Glutathione S-transferase placental form), particularly SMC and cysteine which caused significant reduction in the numbers and areas of GST-P-positive foci.

In addition, the World Health Organization supports the use of the onion bulb for the treatment of age-dependent changes in blood vessels and loss of appetite [22].

Furthermore, Mizuho and Shibamoto [23] showed that volatile samples of freeze-dried onions possess potent anti-inflammatory activity as well as a strong antioxidant property. The bioactive compounds in onion have been found to be capable of reducing enzymatic browning and/or oxidoreductase activity [24]. Several researches have shown that sulfhydryl (SH or thiol) compounds are good inhibitors of polyphenol oxidase enzyme (PPO), major enzyme responsible for browning activity in fruits and vegetables [25,26]. Hence, onion extracts could be used as natural food ingredients for prevention of browning caused by PPO [27].

Fennel (Foeniculum vulgare): Fennel is a biennial medicinal and aromatic plant belonging to the family Apiaceae (Umbelliferaceae). It is a highly aromatic and flavourful herb with culinary and medicinal uses. Fennel seeds are anise like in aroma and are used as flavourings in baked goods, meat and fish dishes, ice cream, alcoholic beverages and herb mixtures [28]. Fennel seed extracts have been shown to have potential use in the treatment of glaucoma, as a diuretic and potential drug for hypertension treatment in animal studies. Extensive studies have been done on $F$. vulgare with the conclusion that the chemo preventive effect of fennel is generally attributed to its essential oil. Although, caution should be taken regarding some of the volatile components, in particular estragole (methylchavicol), which has been associated with the development of malignant tumours in rodent. Karlsen, Svendsen, Chingova, and Zolotovitch [29] reported that the major constituents of sweet fennel (var. dulce) and bitter fennel (var. vulgare) include anethole, estragole, and fenchone, and additional 18 compounds extracted in the monoterpene fraction of the fruit vegetable. Alpha-pinene, camphene, $\beta$-pinene, $\alpha$-phellandrene, myrcene, limonene, $\beta$-phellandrene, gamma-terpinene, cis-ocimene, terpinolene, and p-cymene were the minor volatile oil constituents of bitter fennel.

Both sweet and bitter varieties of fennel essential oils contain about $90 \%$ trans-anethole, $20 \%$ fenchone and small amount of limonene, camphor, $\alpha$-pinene, and other additional minor volatile compounds [30]. The essential oils have been reported to possess antiinflammatory, antioxidant and pro-oxidant activities [31]. Anethole has been reported to possess antimicrobial activity (Table 1) [32], and an active estrogenic agent, and a safe antithrombotic agent [33]. Rather et al. [34] reported that anethole increases milk secretion, promote menstruation, facilitates birth, and alleviates the symptoms of the male climacteric and increase libido. However, in some studies, it was shown that dianethole and photoanethole are the actual estrogenic agents $F$. vulgare essential oils have also been shown to possess acaricidal activity against $D$. farina and $D$. pteronyssinus when used in direct contact application, and the biological active volatile constituents responsible have been identified as P-anisaldehyde, (+)-fenchone, (-)-fenchone, thymol and estragol [35]. Phenyl propanoid derivative-Dillapional was found to be the active antimicrobial principle of the $F$. vulgare stem [36]. Studies have shown that the essential oil and acetone extract of fennel exhibit strong antioxidant activity in comparison with butylated hydroxyl anisole (BHA) and butylated hydroxyl toluene (BTA). Fennel essential oils have also been reported to possess hepatoprotective activity [37], anti-hirutism activity [38], and has positive effect on uterine contraction in rats [39].

Carrot (Daucus carota sativus): Daucus is a genus belonging to the Apiaceae family and consist of over 500 species widely spread around the world. For a long time, plants from this family have been used as spices or drugs. Carrot essential oils have been reported to have several bioactive properties such as antibacterial, fungicidal, hepatocellular regenerator, general tonic, and stimulant, lowering of high cholesterol, and cicatrisant [40]. The oils of some subspecies of Daucus carota have been proven to possess antibacterial activity [41,42].

D. carota is the source of sesquiterpenic alcohols, carotol and daucol, and the sesquiterpene beta-caryophyllene. Carotol, one of the major sesquiterpene alcohols of Daucus carota seeds has a probable biogenesis from cis, trans-farnesol. Previous studies have shown that the chemical composition of Daucus species is more dominated by monoterpene hydrocarbons such as a-pinene and sabinene [43]. Jasicka-Misiak et al. [43], isolated the following terpenoids: carotol, $\beta$-caryophyllene, daucol from the volatile components of carrot and tested their antifungal activity on strains of fungi belonging to the Alternaria family and a strain of Acremonium isolated from the surface of carrot seeds. The combination of these three terpeniods produced strong inhibitory effects on mycelium radial growth of Alternaria alternata. Although, it was observed that sesquiterpene $\beta$-caryophyllene failed to have any effect. The activity of carotol was nearly as strong as the commercially available fungicide Funaben T (85\%).

Various volatile compounds such as terpenes and varieties of aliphatic hydrocarbons (alcohol, aldehydes and ketones) isolated by hydro distillation of oils from Daucus species have been shown to have direct activity against many bacteria species. This antimicrobial action is attributed to the lipophilic character of their hydrocarbon skeleton and hydrophilic character of their functional group [44]. The ketone (undecan-2-one) has also been proven to possess both antimicrobial and nematicidal activities (Table 1) [45]. Glis`ic, Mišić, Stamenić, Zizovic, Ašanin, and Skala, [46] also discovered that carotol; the main volatile component isolated from essential oil of carrot fruit is most effective against gram-positive bacteria. Sabinene however exhibited a stronger antimicrobial effect against Bacillus subtilis, which have previously been proven to inhibit growth of Bacillus subtilis by Dorman, and Deans [47]. 


\section{Flower part of vegetables}

Globe Artichoke (Cynara scolymus L.): Many human diseases, including accelerated ageing, cancer, cardiovascular diseases, neurodegenerative diseases and inflammations, are generally linked to increase amount of free radicals [48]. Artichoke is an herbaceous plant native to the Mediterranean Basin. Globe artichoke is mostly used for food. However, various studies have demonstrated the health promoting properties of its extracts. Beta-selinene, one of the volatile constituents found in artichoke, has been reported to exhibit an antioxidant activity [49]. Eugenol and fechone are also some of the volatile components of artichoke with biological activities (Table 1). Fenchone which is found in fennel leaves possess acaricidal activity against $D$. farina and D. pteronyssinus when used as direct contact application. On the other hand, eugenol has been reported to inhibit the reactive oxygen species (ROS) generation, intracellular calcium accumulation, and the subsequent mitochondrial membrane potential collapse [50]. In addition, eugenol inhibits cytochrome $\mathrm{C}$ release, and caspase-3 $\left(\mathrm{CCl}_{4}\right)$ activation induced by oxidized low density lipoprotein (LDL). Another compound found in artichoke is xanthorrihzol, a natural sesquiterpenoid. Xanthorrihzol has been shown to possess protective effect against cisplatin-induced nephrotoxicity [27]. It also exhibits a potent neuroprotective effect on glutamate-induced neurotoxicity and reactive oxygen species (ROS) generation in the murine hippocampal HT22 cell line. $\mathrm{H}_{2} \mathrm{O}_{2}$-induced lipid peroxidation in rat brain homogenates was also found to be subdued by xanthorrihzol [51].

Broccoli (Brassica oleracea L., Italica group): Broccoli is classified in the Italica cultivar group of the species Brassica oleracea. It is a high source of vitamin $\mathrm{C}$, and dietary fibre; it also contains multiple nutrients with potent anti-cancer properties, such as diindolylmethane and small amounts of selenium. Epidemiological observations suggested that high intake of fruit and vegetables could be associated with a reduced risk of cancer [3], and cruciferous vegetables, including broccoli, cabbage, cauliflower, and Brussels sprouts, seemed particularly beneficial in preventing carcinogenesis [52]. Researchers have shown that the volatile constituents responsible for these activities were the sulphur containing compounds, such as isothiocyanates (R-NCS) and their glucosinolate precursors [53], and indole-based constituents, such as indole-3-carbinol, 3,3'-di-indolylmethane, and indole-3acetonitrile [54]. These volatile constituents were found to induce drug-metabolizing enzymes in cell culture and rodent tissue, and their chemopreventive activity was attributed to the increased detoxification of xenobiotic and carcinogens $[55,56]$.

When broccoli cell structure is ruptured during processing, enzyme myrosinase comes into contact with glucoraphanin to form isothiocyanate sulforaphane (SF; 1-isothiocyanato-4methylsulfinylbutane), and the related nitrile [57]. Sulforaphane has been considered to be the principal component responsible for the cancer prevention of broccoli [58]. Sulforaphane, an aliphatic isothiocyanate, has been isolated from broccoli as the major inducer of Phase II drug-metabolizing enzymes [59,60]. Isothiocyanate sulforaphane (ITCs) has been shown to inhibit tumor genesis which is induced by a wide variety of chemical carcinogens in animal models [61].

Cauliflower (Brassica oleracea Botrytis): Cauliflower like other Brassica family has the capacity to prevent cardiovascular diseases as well as to exert activity against some type of cancers [52]. Violet cauliflower extracts have shown significant antioxidant properties [62]. Pedras, Sarwar, Suchy, and Adio [63] isolated 3 different phytoalexins (secondary metabolites) from cauliflower which contain indolyldisulfide and non-sulphur containing indolyl phytoalexin. The caulilexin A, an example of indolyldisulfide exhibited the most antifungal activity against S. sclerotiorum. Isothiocyanate (ITCs) an enzymatic hydrolysis product of glucosinolate is particularly effective in inhibiting the germination of fungal pathogens: B.cinerea, R. stolonifer, M. lazea, $M$. piriformis and P. expansum [64]. Sisti, Amagliani, and Brandi [65] also showed that $B$. oleraceae aqueous juice was able to inhibit $C$. albicans growth in a dose-dependent manner. Over $95 \%$ inhibition was recorded after $4 \mathrm{~h}$ of incubation with $15 \%$ juice. Cauliflower is also a good source of sulphur-containing volatiles and ITCs. Epidemiological studies have shown evidences over the years, that diet relatively high in cruciferous vegetable can reduce the risk incidence or progression of cancer.

\section{The leaf part of vegetables}

Arugula (Eruca vesicaria subsp. Sativa): Arugula also known as salad rocket is from the same Brassiceae family as cabbage, broccoli and cauliflower. Several researches have been conducted to identify the main volatile constituents responsible for these protective effects of Brassiceae vegetables [66]. One study identified 4-methylthiobutyl glucosinolate (glucoerucin), while another attributed the effects to the presence of 4-mercaptobutyl glucosinolate (glucosativin) [67]. The major volatile compounds in Arugula include sulphur/ nitrogen containing compounds (4-methyliobutyl isothiocyanate and 5-methylthiopentanenitrile), fatty acids, esters, and also volatile aglycones [68]. Villatoro-Pulido, Font, Saha, Obregón-Cano, Anter, Muñoz-Serrano [69] also revealed that Arugula extracts and its sulforaphane were able to detoxify the genotoxic activity of hydrogen peroxide with inhibition rates ranging from 0.13-0.93. In addition, a possible association was established between the consumption of arugula and the antioxidant defence system of mammals.

Arugula has been reported to have the following properties: antiacid, diuretic, astringent, anti-inflammatory for colitis, laxative, antiphlogistic and an aid in digestion [70]. They have also been used as biological controls to inhibit pest development [71]. Lamy et al. [72] reported the chemopreventive potency of arugula extracts in HepG2 cells. They observed that Arugula exhibited anti-genotoxicity by reducing the benzo $(\alpha)$ pyrene-induced genotoxicity in a U-shaped manner, and that the compounds responsible for this chemopreventive activity were identified as isothiocyanate erucin, sulforaphane, erysolin and phenylethyl isothiocyanate. Literature survey reveals that Arugula leaves are antiscorbutic, diuretic, stimulant and stomachic while the seed and seed powder have rubefacient and antibacterial properties respectively [73]. Rani et al. [74] also showed that both crude water extract and methanolic extract of Arugula exhibited varying degrees of microbial inhibition. Water extract showed moderate antifungal activity against Spadicoides stoveri and Paecilomyces variotii, while it showed significant antibacterial activity against Hafnia alvei and Enterobacter agglumerans.

Water dropwort (Oenanthe javanica): Water dropwort belongs to the family Umbelliferae and it is cultivated in marshy places of Asia and Australia. Water dropwort is known to have antimutagenic effect against aflatoxin B1 and a capacity to remove heavy metals, such as Cadmium [75]. The principal volatile compounds of water dropwort were $\alpha$-copaene, caryophyllene, $\alpha$-cuprene, and a cembrene-type diterpene, incensole [76]. Recent studies have shown that incensole and its acetylated form incensole acetate, exhibits anti-inflammatory effect as well as several CNS-associated activities [77,78]. Similarly, tricyclic sesquiterpene, copaene has been shown to exhibit antioxidant and anti-carcinogenic features [79]. 


\section{Stem part of vegetables}

Celery (Apium graveolens): Celery belongs to the family Umbelliferae and it grows wild in Europe, the Mediterranean region and in Asia, west of the Himalayas. Seeds of the celery plant have been used for thousands of years in Ayurveda medicine. The volatile extracts of celery seeds are used in the perfume and pharmaceutical industries. All parts of this vegetable are known to be a remedy for one or more maladies. It has been reported to have insecticidal, bactericidal [80], and chemostatic effects [81]. The principal volatile constituents of celery are limonene, $\beta$-selinene, $\beta$-caryophyllene, sedanolde, cis-ocimene, apiole, 3-butylphthalide, myrcene and 3-butyl-4,5dihydrophthalide, $[82,83]$. Jawad, Suvarnalatha, Sankar, and Suresh [84] reported that sesquiterpene lactones from A. graveolens exhibited antimicrobial activity against Bacillus subtilis, Proteus vulgaris, and tested fungi, while Siapailene, Venskutonis, Sarkinas, and Cypiene [85] showed that root extracts which composed more of trans-ocimene, 3-methyl-4-ethylhexane and $\beta$-pinene [86] have high activity against B.cereus and Enterococcus faecalis. Celery has been used traditionally to treat many ailments such as rheumatism, rheumatoid arthritis, diuresis, and indigestion [87]. Alcoholic extracts of celery roots have been used to cure urinary disorders such as urinary stone, and used as kidney stimulant and cleanser. Furthermore, several studies have reported that celery seed has been useful for the treatment of urinary calculi, gut diseases, flatulence and gripping pains, reduction of visceral spasm and stimulation of the smooth muscle of the womb. Phthalide a constituent of celery seed has been associated with the above effects $[88,89]$. Celery has also been reported to reduce blood sugar, and thus may be useful as an anti-diabetic agent. Both ethanol and methanol extracts of celery seed have been shown to possess bioactive volatile constituents. Ethanolic extracts of celery leaves have been reported to have anti-inflammatory and antiulcer activity in rodent models, while methanolic extract possess antifungal, insecticidal and nematicidal effects [90]. Friedman, et al. [80] also reported the bactericidal effect of celery seed extracts against Campylobacter jejun, Escherichia coli, Listeria monoytogenes and Salmonella enterica. In a study conducted by Zhou, Taylor, Smith, Liu, Clench, Davies, and Rainsford [91] a novel component of celery seed with a dimeric phthalide structure was shown to exhibit a potent antimicrobial activity specifically against Helicobacter pylori.

Cheng et al. [92] have also reported the anti-oxidative and hypolipidemic activity of 9 (Z)-octadecenamide obtained from methanolic fractionate of mountain celery seed oil. The authors' results showed a significant reduction in serum triglyceride, total cholesterol, low-density lipoprotein cholesterol, and hepatic triglyceride. Mencherin et al. [93] have also shown that apiin, a component of ethanol/water extract of celery was able to inhibit inducible nitric oxide (iNOS, NOS-II) and nitric oxide (NO) production in vitro.

Asparagus (Asparagus officinalis): Asparagus is a green vegetable popularly consumed in most parts of the world, as salads, vegetable dishes or soups. It has been used as a tonic, antifebrile, antitussive, hair growth stimulator, and diuretic agent in the traditional Chinese medicine [94]. Extracts from the plant have been shown to possess certain biological activities including antifungal, anti-mutagenic, diuretic, cytotoxic, antiviral and molluscicide properties [94]. The principal compounds associated with these biological effects include flavonoids, oligosaccharides, amino acids derivatives, sulphur containing acids, and steroidal saponins [94], with saponin being the major active compound responsible for these effects in asparagus. Saponins are one of the many secondary metabolites found in plant species, which structurally contains hydrophilic glycoside moieties and lipophilic triterpene derivatives. Shao, et al. [94] reported the antitumor property of crude saponin from asparagus extract. Results from their investigation showed that asparagus crude saponin inhibited the growth of human leukaemia HL-60 cells and the synthesis of macromolecules in HL- 60 cells, although, the possible mechanism of saponin was not addressed.

\section{Conclusion and Future Trend}

Understanding the chemo-preventive activities of vegetables can stimulate an interest in maximizing their utilization in human diet. The current status of research on some volatile organic compounds in common vegetable and their potential roles in the prevention of various diseases are reviewed. The volatile organic compounds with roles in health promoting activities in vegetables are Benzene propane nitrile, 1H-Indole-3-acetonitrile, Xanthorrihzol, Thymol, Carvarol, terpenoids, capsaicin, and glucosinolates. Although several biological effects based on epidemiological studies can be scientifically explained, the mechanism of action of some effects of the above named compounds is not fully understood. A better knowledge of some variables of VOCs bioavailability; such as the kinetics of absorption, accumulation and elimination, will facilitate the design of such studies. The role of volatile organic compounds in health is still a fertile area of researches.

\section{References}

1. Vaughan J, Geissler C (2009) The new Oxford book of food plants. Oxford University Press.

2. Gary T (1999) Flavour chemistry of vegetables. In: Teranish R, Wick EL, Hornstein I, editors, Flavour Chemistry Thirty Years of Progress. New York Kluwer Academic Plenum Publishers: 287-304.

3. Steinmetz KA, Potter JD (1991) Vegetables, fruit, and cancer. I. Epidemiology See comment in PubMed Commons below Cancer Causes Control 2: 325-357.

4. Dragsted LO, Strube M, Larsen JC (1993) Cancer-protective factors in fruits and vegetables: biochemical and biological background. See comment in PubMed Commons below Pharmacol Toxicol 72 Suppl 1: 116-135.

5. Liu S, Manson JE, Lee IM, Cole SR, Hennekens CH, et al. (2000) Fruit and vegetable intake and risk of cardiovascular disease: the Women's Health Study. See comment in PubMed Commons below Am J Clin Nutr 72: 922-928.

6. Riboli E1, Norat T (2003) Epidemiologic evidence of the protective effect of fruit and vegetables on cancer risk. See comment in PubMed Commons below Am J ClinNutr 78: 559S-569S.

7. Osuna-García JA, Wall MM, Waddell CA (1998) Endogenous levels of tocopherols and ascorbic acid during fruit ripening of New Mexican-type chili (Capsicum annuum L.) cultivars. J of Agri and Food Chem 46: 5093-5096.

8. Ivbijaro MF, Agbaje M (1986) Insecticidal activities of piper guineenseschum and Thonn, and capsicum species on the cowpea branched, Callosobruchus maculates. Insect Sci App 7: 521-524.

9. Buttery RG, Seifert RM, Guadagni DG, Ling LC (1969) Characterization of some volatile constituents of bell peppers. See comment in PubMed Commons below J Agric Food Chem 17: 1322-1327.

10. Perry LM, Metzger J (1980) Medicinal plants of east and southeast Asia attributed properties and uses. MIT press.

11. Izumitani Y, Yahara S, Nohara T (1990) Novel acyclic diterpene glycosides, capsianosides AF and IV from Capsicum plants (Solanaceous studies. XVI). Chem and Pharm Bul 38: 1299-1307.

12. Yahara S, Kobayashi N, Izumitani $Y$, Nohara $T$ (1991) Studies on the solanaceous plants. 23 new acyclic diterpene glycosides, capsianoside-vi, capsianoside-g and capsianoside-h from the leaves and stems of Capsicumannuum-L. Chem and Pharm Bul 39: 3258-3260.

13. Kirkbride JH (1993) Biosystematic monograph of the genus Cucumis (Cucurbitaceae): botanical identification of cucumbers and melons. Parkway Publishers, Inc. 
14. Guha J, Sen SP (1975) Thecucurbitacins-a review. Plant Biochem J 2: 12-28.

15. Sotiroudis G, Melliou E, Sotiroudis TG, Chinou I (2010) Chemical analysis antioxidant and antimicrobial activity of three Greek cucumber (Cucumissativus) cultivars. J of Food Biochem, 34: 61-78.

16. Fosse C, Le Texier L, Roy S, Delaforge M, Grégoire S, et al. (2004) Parameters and mechanistic studies on the oxidative ring cleavage of synthetic heterocyclic naphthoquinones by Streptomyces strains. See comment in PubMed Commons below Appl Microbiol Biotechnol 65: 446-456.

17. Stratil P, Klejdus B, Kubán V (2006) Determination of total content of phenolic compounds and their antioxidant activity in vegetables--evaluation of spectrophotometric methods. See comment in PubMed Commons below $J$ Agric Food Chem 54: 607-616.

18. Block E (1992) Theorganosulfur chemistry of the genus Allium-implications for the organic chemistry of sulphur. Angewandte Chemielnt Ed in Eng 31: 11351178.

19. Xiao H, Parkin KL (2002) Antioxidant functions of selected allium thiosulfinates and S-alk(en)yl-L-cysteine sulfoxides. See comment in PubMed Commons below J Agric Food Chem 50: 2488-2493.

20. Wargovich MJ (1987) Diallyl sulfide, a flavor component of garlic (Allium sativum), inhibits dimethylhydrazine-induced colon cancer. See comment in PubMed Commons below Carcinogenesis 8: 487-489.

21. Fukushima S1, Takada N, Hori T, Wanibuchi H (1997) Cancer prevention by organosulfur compounds from garlic and onion. See comment in PubMed Commons below J Cell Biochem Suppl 27: 100-105.

22. World Health Organization (2002) WHO monographs on selected medicinal plants (Vol.2) World Health Organization.

23. Takahashi M1, Shibamoto T (2008) Chemical compositions and antioxidant/ anti-inflammatory activities of steam distillate from freeze-dried onion Alliumcepa L.) sprout. See comment in PubMed Commons below J Agric Food Chem 56: 10462-10467.

24. Eissa HA, Fadel HH, Ibrahim GE, Hassan IM, Elrashid AA (2006) Thio containing compounds as controlling agents of enzymatic browning in some apple products. Food Re Int 39: 855-863.

25. Jang MS, Sanada A, Ushio H, Tanaka M, Ohshima T (2002) Inhibitory effects of 'Enokitake'mushroom extracts on polyphenol oxidase and prevention of apple browning. LWT-Food Sci and Tech 35: 697-702.

26. Negishi O, Ozawa T (2000) Inhibition of enzymatic browning and protection of sulfhydryl enzymes by thiol compounds. See comment in PubMed Commons below Phytochemistry 54: 481-487.

27. Kim MJ, Kim CY, Park I (2005) Prevention of enzymatic browning of pear by onion extract. Food Chem 89: 181-184.

28. Díaz-Maroto MC, Díaz-Maroto HIJ, Sánchez-Palomo E, Pérez-Coello MS (2005) Volatile components and key odorants of fennel (Foeniculumvulgare Mill.) and thyme (Thymus vulgaris L.) oil extracts obtained by simultaneous distillation-extraction and supercritical fluid extraction. J of Agri and Food Chem 53: 5385-5389.

29. Karlsen J, Svendsen AB, Chingova B, Zolotovitch G (1969) Studies on the fruits of Foeniculum species and their essential oil. See comment in PubMed Commons below Planta Med 17: 281-293.

30. Conforti F, Statti G, Uzunov D, Menichini F (2006) Comparative chemical composition and antioxidant activities of wild and cultivated Laurusnobilis L. leaves and Foeniculumvulgaresubsp. piperitum (Ucria) coutinho seeds. Bio and Pharm Bul 29: 2056.

31. Miguel MG, Cruz C, Faleiro L, Simões MT, Figueiredo AC, et al. (2010) Foeniculumvulgare essential oils: chemical composition, antioxidant and antimicrobial activities. See comment in PubMed Commons below Nat Prod Commun 5: 319-328.

32. Kubo I, Fujita KI, Nihei KI (2008) Antimicrobial activity of anethole and related compounds from aniseed. $\mathrm{J}$ of the Sci of Food and Agri 88: 242-247.

33. Tognolini M, Ballabeni V, Bertoni S, Bruni R, Impicciatore M, et al. (2007) Protective effect of Foeniculumvulgare essential oil and anethole in an experimental model of thrombosis. See comment in PubMed Commons below Pharmacol Res 56: 254-260.

34. Rather MA, Dar BA, Sofi SN, Bhat BA, Qurishi MA (2012) Foeniculumvulgare:
A comprehensive review of its traditional use, phytochemistry, pharmacology, and safety.

35. Lee HS (2004) Acaricidal activity of constituents identified in Foeniculumvulgare fruit oil against Dermatophagoides spp. (Acari: Pyroglyphidae). See comment in PubMed Commons below J Agric Food Chem 52: 2887-2889.

36. Kwon YS, Choi WG, Kim WJ, Kim WK, Kim MJ, et al. (2002) Antimicrobial constituents of Foeniculumvulgare. See comment in PubMed Commons below Arch Pharm Res 25: 154-157.

37. Ozbek H, UÄŸraÅ̈̈ S, DÃ $1 / 4 \operatorname{lger} H$, Bayram I, Tuncer I, et al. (2003) Hepatoprotective effect of Foeniculumvulgare essential oil. See comment in PubMed Commons below Fitoterapia 74: 317-319.

38. Javidnia K, Dastgheib L, MohammadiSamani S, Nasiri A (2003) Antihirsutism activity of Fennel (fruits of Foeniculumvulgare) extract. A double-blind placebo controlled study. See comment in PubMed Commons below Phytomedicine 10: $455-458$

39. Ostad SN, Soodi M, Shariffzadeh M, Khorshidi N, Marzban H (2001) The effect of fennel essential oil on uterine contraction as a model for dysmenorrhea, pharmacology and toxicology study. See comment in PubMed Commons below J Ethnopharmacol 76: 299-304

40. Zizovic I, Stamenić M, Orlović A, Skala D (2007) Supercritical carbon dioxide extraction of essential oils from plants with secretory ducts: Mathematical modelling on the micro-scale. The $\mathrm{J}$ of Supercritical Fluids 39: 338-346.

41. Staniszewska M, Kula J, Wieczorkiewicz M, Kusewicz D (2005) Essential oils of wild and cultivated carrots-the chemical composition and antimicrobial activity. J of Ess Oil Res 17: 579-583.

42. Rossi PG, Bao L, Luciani A, Panighi J, Desjobert JM, et al. (2007) (E)Methylisoeugenol and elemicin: antibacterial components of Daucuscarota $L$. essential oil against Campylobacter jejuni. See comment in PubMed Commons below J Agric Food Chem 55: 7332-7336.

43. Jasicka-Misiak I, Lipok J, Nowakowska EM, Wieczorek PP, MÅ,ynarz P, et al. (2004) Antifungal activity of the carrot seed oil and its major sesquiterpene compounds. See comment in PubMed Commons below Z Naturforsch C 59 : 791-796.

44. Bendiabdellah A, El Amine Dib M, Djabou N, Allali H, Tabti B, et al. (2012) Biological activities and volatile constituents of Daucusmuricatus $L$. from Algeria. See comment in PubMed Commons below Chem Cent J 6: 48.

45. Ntalli NG, Ferrari F, Giannakou I, Menkissoglu-Spiroudi U (2011) Synergistic and antagonistic interactions of terpenes against Meloidogyne incognita and the nematicidal activity of essential oils from seven plants indigenous to Greece. See comment in PubMed Commons below Pest ManagSci 67: 341-351.

46. Glišic SB, Mišic DR, Stamenic MD, Zizovic IT, Ašanin RM, et al (2007) Supercritical carbon dioxide extraction of carrot fruit essential oil: Chemical composition and antimicrobial activity. Food Chem 105: 346-352.

47. Dorman HJ, Deans SG (2000) Antimicrobial agents from plants: antibacteria activity of plant volatile oils. See comment in PubMed Commons below $J$ ApplMicrobiol 88: 308-316.

48. Moskovitz J, Yim MB, Chock PB (2002) Free radicals and disease. See comment in PubMed Commons below Arch BiochemBiophys 397: 354-359.

49. Ou HC, Chou FP, Lin TM, Yang CH, Sheu WHH (2006) Protective effects of eugenol against oxidized LDL-induced cytotoxicity and adhesion molecule expression in endothelial cells. Food and ChemTox 44: 1485-1495.

50. Mizutani T, Satoh K, Nomura H, Nakanishi K (1991) Hepatotoxicity of eugenol in mice depleted of glutathione by treatment with DL-buthioninesulfoximine. See comment in PubMed Commons below Res CommunChemPatholPharmacol 71: 219-230.

51. Lim CS, Jin DQ, Mok H, Oh SJ, Lee JU, et al.(2005) Antioxidant and antiinflammatory activities of xanthorrhizol in hippocampal neurons and primary cultured microglia. See comment in PubMed Commons below J Neurosci Res 82: 831-838.

52. Beecher DJ, Wong AC (1994) Identification and analysis of the antigens detected by two commercial Bacillus cereus diarrheal enterotoxin immunoassay kits. App and EnvMicrob 60: 4614-4616.

53. Stoewsand GS (1995) Bioactiveorganosulfur phytochemicals in Brassica oleracea vegetables--a review. See comment in PubMed Commons below Food Chem Toxicol 33: 537-543. 
Citation: Lasekan O, Azeez S (2014) Chemo-preventive Activities of Common Vegetables' Volatile Organic Compounds (VOCs). Pharm Anal Acta 5: 306. doi:10.4172/2153-2435.1000306

54. Wattenberg LW, Loub WD (1978) Inhibition of polycyclic aromatic hydrocarboninduced neoplasia by naturally occurring indoles. See comment in PubMed Commons below Cancer Res 38: 1410-1413.

55. Bjeldanes LF, Kim JY, Grose KR, Bartholomew JC, Bradfield CA (1991) Aromatic hydrocarbon responsiveness-receptor agonists generated from indole-3carbinol in vitro and in vivo: comparisons with 2, 3, 7, 8-tetrachlorodibenzo-pdioxin. Proceedings of the Nat Aca of Sci 88: 9543-9547.

56. Bradfield CA, Bjeldanes LF (1991) Modification of carcinogen metabolism by indolylic autolysis products of Brassicaoleraceae. Adv Exp Med Biol 289: 153163

57. Matusheski NV, Juvik JA, Jeffery EH (2004) Heating decreases epithiospecifier protein activity and increases sulforaphane formation in broccoli. See comment in PubMed Commons below Phytochemistry 65: 1273-1281.

58. Fahey JW, Zhang Y, Talalay P (1997) Broccoli sprouts: an exceptionally rich source of inducers of enzymes that protect against chemical carcinogens. See comment in PubMed Commons below Proc Natl Acad Sci U S A 94: 10367 10372.

59. Zhang Y, Talalay P, Cho CG, Posner GH (1992) A major inducer of anticarcinogenic protective enzymes from broccoli: isolation and elucidation of structure. See comment in PubMed Commons below Proc Natl Acad Sci U S A 89: 2399-2403

60. Prestera T, Holtzclaw WD, Zhang Y, Talalay P (1993) Chemical and molecular regulation of enzymes that detoxify carcinogens. See comment in PubMed Commons below Proc Natl Acad Sci U S A 90: 2965-2969.

61. Hecht SS (1995) Chemoprevention by isothiocyanates. See comment in PubMed Commons below J Cell Biochem Suppl 22: 195-209.

62. Pizzo-caro F, Ferrari V, Acciarri N, Morelli R, Russo-Volpe S, et.al (2000) Antioxidant and antiradical activities in green and violet cauliflower ecotypes with different maturity stages. In Workshop of VI Giornate Scientifiche SOI, Sirmione 28: 34-35.

63. Pedras MS, Sarwar MG, Suchy M, Adio AM (2006) The phytoalexins from cauliflower, caulilexins $A, B$ and $C$ : isolation, structure determination, syntheses and antifungal activity. See comment in PubMed Commons below Phytochemistry 67: 1503-1509.

64. Mari M, lori R, Leoni O, Marchi A (1993) In vitroactivity of glucosinolate-derived isothiocyanates against postharvest fruit pathogens.Anal of App Bio 123: 155164

65. Sisti M1, Amagliani G, Brandi G (2003) Antifungal activity of Brassica oleracea var. botrytis fresh aqueous juice. See comment in PubMed Commons below Fitoterapia 74: 453-458

66. Higdon JV, Delage B, Williams DE, Dashwood RH (2007) Cruciferous vegetables and human cancer risk: epidemiologic evidence and mechanistic basis. See comment in PubMed Commons below Pharmacol Res 55: 224-236.

67. Bennett RN, Mellon FA, Botting NP, Eagles J, Rosa EA, et al. (2002) Identification of the major glucosinolate (4-mercaptobutyl glucosinolate) in leaves of Eruca sativa L. (salad rocket). See comment in PubMed Commons below Phytochemistry 61: 25-30.

68. Blaževic I, Mastelic J (2008) Free and bound volatiles of rocket (Eruca sativa Mill.) Flav and Frag J 23: 278-285

69. Villatoro-Pulido M, Font R, Saha S, Obregón-Cano S, Anter J, Muñoz-Serrano A (2012) In vivo biological activity of rocket extracts Erucavesicaria sub. sp. sativa (Miller) Thell) and sulforaphane. Food and Chem Tox 50: 1384-1392.

70. De Feo V, Senatore F (1993) Medicinal plants and phytotherapy in the Amalfitan Coast, Salerno Province, Campania, southern Italy. See comment in PubMed Commons below J Ethnopharmacol 39: 39-51.

71. Yaniv Z (1996) Traditions, uses and research on rocket in Israel. In Rocket: a Mediterranean crop for the world. Report of a Workshop: 13-14.

72. Lamy E, Schröder J, Paulus S, Brenk P, Stahl T, et al. (2008) Antigenotoxic properties of Eruca sativa (rocket plant), erucin and erysolin in human hepatoma (HepG2) cells towards benzo(a)pyrene and their mode of action. See comment in PubMed Commons below Food Chem Toxicol 46: 2415-2421.

73. Chopra RN, Nayar SL, Chopra IC (1986) Glossary of Indian Medicinal Plants (Including the Supplement). Coun of Scien and Ind Res, New Delhi.

74. Rani I, Akhund S, Suhail M, Abro H (2010) Antimicrobial Potential of Seed Extract of Eruca Sativa. Pakistanian J of Bot 42: 2949-2953.
75. Seo $\mathrm{WH}$, Baek $\mathrm{HH}$ (2005) Identification of characteristic aroma-active compounds from water dropwort (Oenanthejavanica DC.). See comment in PubMed Commons below J Agric Food Chem 53: 6766-6770.

76. Pattiram PD, Lasekan O, Tan CP, Zaidul ISM (2011) Identification of the aroma-active constituents of the essential oils of water dropwort and kacip Fatimah (Labisiapumila) Int. Food Res J 18: 979-984

77. Moussaieff A, Shohami E, Kashman Y, Fride E, Schmitz ML, et al. (2007) Incensole acetate, a novel anti-inflammatory compound isolated from Boswellia resin, inhibits nuclear factor-kappa B activation. See comment in PubMed Commons below Mol Pharmacol 72: 1657-1664

78. Moussaieff A, Rimmerman N, Bregman T, Straiker A, Felder CC, et al. (2008) Incensole acetate, an incense component, elicits psychoactivity by activating TRPV3 channels in the brain. See comment in PubMed Commons below FASEB J 22: 3024-3034

79. Turkez H, Togar B, Tatar A (2014) Tricyclic sesquiterpenecopaene prevents $\mathrm{H} 2$ O2 induced neurotoxicity. J Intercult Ethnopharm 3: 21-28

80. Friedman M, Henika PR, Mandrell RE (2002) Bactericidal activities of plant essential oils and some of their isolated constituents against Campylobacter jejuni,Escherichia coli,Listeria monocytogenes, and Salmonella enterica. J of Food Protection 65: 1545-1560.

81. Saleh MM, Zwaving JH, Malingré TM, Bos R (1985) The essential oil of Apiumgraveolensvar. secalinum and its cercaricidal activity. See comment in PubMed Commons below Pharm Weekbl Sci 7: 277-279.

82. Ehiabhi OS, Edet UU, Walker TM, Schmidt JM, Setzer WN et.al (2006) Constituents of Essential Oils of ApiumgraveolensL., Allium cepaL., and Voacangaafricana Staph from Nigeria. J of Ess Oil Bearing Plants 9: 126-132

83. Philippe J, Suvarnalatha G, Sankar R, Suresh S (2002) Kessane in the Indian celery seed oils. J of Ess Oil Res 14: 276-277.

84. Jawad AL, Dhahir AB, Hussain AM (1985) Preliminary studies on the antimicrobial activity of sesquiterpene lactones extracted from Iraqi Compositae. Part I. J of Bio Sci Res 16: 5-18.

85. Siapailene A, Venskutonis PR, Sarkinas A, Cypiene V (2003) Composition and antimicrobial activity of celery (Apiumgraveolens) leaf and root extracts obtained with liquid carbon dioxide. In III WOCMAP Congress on Medicinal and Aromatic Plants-Volume 3: Perspectives in Nat Prod Chem 677: 71-77.

86. Fehr D (1981) Investigations into the aromatic compounds of celery. Part 2 Pharmazie 36: 374-376.

87. Houghton P (1995) Herbal products. 9. Bearberry, dandelion and celery. Pharm J 255: 272-273

88. Oiye SO, Muroki NM (2002) Use of spices in Foods. J of Food Tech in Africa 7: $39-44$.

89. Riddle JM (2004) Kidney and urinary therapeutics in early medieval monastic medicine. See comment in PubMed Commons below J Nephrol 17: 324-328.

90. Momin RA, Nair MG (2001) Mosquitocidal, nematicidal, and antifungal compounds fromApiumgraveolens $\mathrm{L}$. seeds. See comment in PubMed Commons below J Agric Food Chem 49: 142-145.

91. Zhou Y, Taylor B, Smith TJ, Liu ZP, Clench M, et al. (2009) A novel compound from celery seed with a bactericidal effect against Helicobacter pylori. See comment in PubMed Commons below J Pharm Pharmacol 61: 1067-1077.

92. Cheng MC, Ker YB, Yu TH, Lin LY, Peng RY, et al. (2010) Chemical synthesis of $9(Z)$-octadecenamide and its hypolipidemic effect: a bioactive agent found in the essential oil of mountain celery seeds. See comment in PubMed Commons below J Agric Food Chem 58: 1502-1508.

93. Mencherini T, Cau A, Bianco G, Della Loggia R, Aquino RP, et al. (2007) An extract of Apiumgraveolens var. dulce leaves: structure of the major constituent apiin, and its anti-inflammatory properties. See comment in PubMed Commons below J Pharm Pharmacol 59: 891-897.

94. Shao Y, Chin CK, Ho CT, Ma W, Garrison SA, et al. (1996) Anti-tumor activity of the crude saponins obtained from asparagus. See comment in PubMed Commons below Cancer Lett 104: 31-36. 